\title{
A escola como espaço de formação de professores em comunidade: $O$ movimento de pensar o desenvolvimento de projetos investigativos em Ciências
}

\section{The school as a space for teachers formation in a community: The movement to think about the development of investigative projects in Science}

Karlene Tatiana Kolling (karlenetatiana@gmail.com)

Programa de Pós-Graduação em Ensino de Ciências Exatas - Universidade Federal do Rio Grande Campus Santo Antônio da Patrulha

Resumo: O presente trabalho traz o relato de um projeto investigativo em Ciências desenvolvido em uma turma de quinto ano, do Ensino Fundamental, da Escola Estadual de Ensino Médio Berthalina Kirsch, localizada na cidade de Igrejinha/RS. Nesse contexto, a pesquisa em sala de aula proporcionou movimentos pedagógicos colaborativos entre professores no sentido de promover a interdisciplinaridade e oportunizar o protagonismo estudantil. Ademais, evidenciou a importância da alfabetização e da argumentação científicas, buscando parcerias entre escolas e considerando a mostra do conhecimento como um espaço-tempo não formal de formação permanente. Além disso, aproximou a escola da Universidade por meio do I Curso Online de Formação de Professores sobre Feiras e Mostras Científicas promovido pela Universidade Federal do Rio Grande (FURG), destacando, assim, a relevância de um ressignificar constante das práticas docentes, quando os saberes-fazeres de cada professor(a) se mostram como objetos a serem constantemente aperfeiçoados. Sendo assim, o projeto interdisciplinar "Borboletas: de um verso para o universo" se mostrou como um cenário em que os sujeitos envolvidos, unidos por um objetivo em comum, construíram conhecimentos significativos por meio de interações dialógicas e mediações pedagógicas alicerçadas na partilha de experiências e na potencialidade da escola enquanto espaço de formação de professores em comunidade.

Palavras-chave: Projetos investigativos em Ciências; Formação continuada de professores; Interdisciplinaridade.

Abstract: This work brings the report of an investigative project in Sciences developed in a Fifth Year class, at Berthalina Kirsch State High School, located in Igrejinha town, RS. In this context, the classroom research provided collaborative pedagogical movements among teachers in order to promote interdisciplinarity and opportunize student protagonism. In addition, it highlighted the importance of scientific literacy and argumentation, seeking partnerships between schools and considering the display of knowledge as a non-formal space-time of ongoing formation. Additionally, it brought the school closer to the University through the 1st Online Teacher Training Course on Fairs and Scientific Shows promoted by the Federal University of Rio Grande - FURG, thus highlighting the relevance of a constant resignification of teaching practices, where the knowledge of each teacher is shown as objects to be constantly improved. Consequentely, the interdisciplinary project: "Butterflies: from a verse to the universe" has shown itself as a scenario where the subjects involved, united by a common goal, have built significant knowledge through dialogical interactions, pedagogical 
Edição Especial: XVI Encontro sobre Investigação na Escola - EIE

mediations based on sharing experiences and on the potentiality of the school as a space for training teachers in the community.

Keywords: Investigative projects in Sciences; Continuous teacher training; Interdisciplinarity.

\section{INTRODUÇÃO}

A formação de professores é um tema relevante e instigante, pois nela reside uma trajetória que, individualmente, tem início no magistério, na licenciatura ou na especialização. Porém, a sua efetivação acontece de fato no exercício da docência, durante a caminhada, de maneira contínua, mas, principalmente, nas relações colaborativas que são estabelecidas nas escolas. A carreira vai sendo construída em diferentes tempos e em diferentes espaços, mas especialmente em serviço, a cada desafio pedagógico que se apresenta dentro da dinâmica do espaço escolar.

Sendo assim, as práticas se mostram como possibilidades de constituição de movimentos pedagógicos alicerçados na socialização de experiências que permitem a formação de maneira continuada, de acordo com os assuntos ou temas de interesse de cada docente. Surge aí a filiação a uma ou outra corrente de teorias pedagógicas, uma identificação com a atuação de um ou outro grupo de colegas, uma afinidade com assuntos de interesse comuns e um compromisso maior consigo mesmo que é em relação à autoria de seu fazer pedagógico.

Diante dessa realidade, a formação permanente se mostra como um leque de possibilidades em que os docentes envolvidos podem fazer escolhas de caminhos a serem percorridos para alcançar os objetivos a que se propõem dentro das temáticas que os desafiam enquanto pesquisadores-autores. A partir disso, acreditamos que uma comunidade de indagação dialógica, estruturada por meio da pesquisa-ação colaborativa, seja um dos possíveis caminhos para um repensar crítico-reflexivo especialmente da pesquisa em Ciências.

A partir daí, emerge o entendimento da importância de uma comunidade de indagação dialógica fazer parcerias, pois a colaboração a coloca em uma perspectiva de ações coletivas que objetivam a qualificação profissional de todos os envolvidos. Uma possibilidade é buscar, nas universidades, a colaboração dos professores universitários e, nesse sentido, Pimenta (1999, p. 9) reforça a necessidade de “[...] criar uma cultura de análise das práticas nas escolas, tendo em vista suas transformações pelos professores, com a colaboração dos professores universitários". 


\section{CONTEXTO E DETALHAMENTO DAS ATIVIDADES}

A escola é, por excelência, um espaço de construção do conhecimento. Nela se encontram pessoas cujos papéis se entrelaçam, e essa interação colaborativa favorece o nascimento da pesquisa por meio de projetos investigativos que surgem do interesse e da curiosidade dos estudantes. Segundo Guidotti e Araújo (2020, p. 54), "No contexto da pesquisa em sala de aula, a curiosidade epistemológica está conexa ao ato de investigar, de olhar para o objeto de estudo de forma indagativa e cuidadosa". Os autores se referem a "[...] uma curiosidade metódica, que exige dos estudantes ações de engajamento na construção ativa do conhecimento". Os professores, também pesquisadores, se envolvem nessas buscas e auxiliam os estudantes atuando como mediadores do conhecimento, ou seja, favorecem a tecitura de conexões entre o que está inquietando os sujeitos e a construção do conhecimento de maneira significativa, prazerosa e visível.

Diante desse entendimento, os vinte e oito estudantes da turma do quinto ano do Ensino Fundamental da Escola Estadual de Ensino Médio Berthalina Kirsch, localizada na cidade de Igrejinha, RS, puderam contar, além da professora titular e unidocente, com o apoio de outros docentes, especialmente das áreas atuantes no Ensino Médio e com parcerias dentro e fora da instituição para fazer o seu itinerário de pesquisa em um projeto investigativo interdisciplinar. A partir do verso do poeta gaúcho Mario Quintana: "O segredo é não correr atrás das borboletas... É cuidar do jardim para que elas venham até você", a turma se encantou com a possibilidade de pesquisar sobre as borboletas, seu ciclo de vida e sobre as condições favoráveis para que as diferentes espécies possam continuar existindo sem a ameaça de extinção. Além disso, os estudantes se mostraram dispostos a refletir sobre o planeta Terra como habitat de todas as espécies de vida existentes e do quanto cada um(a) é responsável pela manutenção dos ecossistemas.

Sendo assim, construíram a seguinte justificativa para a viabilização do seu projeto de pesquisa: "Escolhemos este assunto para conscientizar as pessoas sobre a necessidade de olhar, cuidar, repensar, proteger, responsabilizar-se e desenvolver ações para garantir que todas as formas de vida na Terra possam continuar existindo." Portanto, o projeto "Borboletas: de um verso para o universo" se apresenta como uma possibilidade de repensar atitudes e de promover a conscientização através de vivências significativas e prazerosas em parceria com o 
Centro de Atividades Ambientais Augusto Kampff no tema Biodiversidade - CEAAK \& Escola em Ação e na turma 151, mas que se estendeu a toda a escola e, consequentemente, a toda a comunidade escolar do bairro Viaduto, no ano letivo de dois mil e dezenove.

Rubem Alves (2013), a partir do vídeo A Escola Ideal, nos convida a pensar sobre o papel do professor nesse contexto como alguém que "[...] aguça a curiosidade e cria a alegria de pensar". Segundo ele, “[...] a missão do professor é provocar a inteligência, e não dar respostas prontas, pois as respostas prontas estão nos livros”.

A partir daí, os estudantes passam a experienciar a autonomia em relação à construção do conhecimento, pois vivenciam uma relação dialógica, em que o professor, à medida que ensina, também aprende, e isso, segundo Paulo Freire (1996), é um processo democrático e afetivo em se tratando de ensino e de aprendizagem. Estudantes, mediados por seus professores, se apropriam do conhecimento e, em uma espiral ascendente, constroem trajetórias que os modificam, pois, como diria Heráclito, "[...] nenhum homem pode banhar-se duas vezes no mesmo rio, pois na segunda vez o rio já não é o mesmo, nem tão pouco o homem”. Sendo assim, a função do professor é desacomodar, tirar da zona de conforto e lançar para além, promovendo o descortinar de novos horizontes que proporcionam novos entendimentos e novas possibilidades.

Nesse contexto, Vygotski (1991) nos proporciona o entendimento do ensino como processo social, ou seja, ele compreende o sujeito como alguém que se constitui em contato com a sociedade. "Sua unidade de análise não é nem o indivíduo nem o contexto, mas a interação entre eles” (MOREIRA, 1999, p. 112). Nessa perspectiva, “[...] a interação social é o veículo fundamental para a transmissão dinâmica (de inter para intrapessoal) do conhecimento social, histórica e culturalmente construído" (MOREIRA, 1999, p. 112). Esse teórico nos possibilita o entendimento de que o contato inicial da criança com novas atividades, habilidades ou informações deve ter a participação de um adulto. Para ele, a resposta está na mediação, ou seja, no caso da escola, o papel do(a) professor(a) é essencial para que os estudantes avancem em seus entendimentos e se apropriem de novos conhecimentos.

Portanto, havia um problema a ser investigado: o que fazer para tomarmos consciência e para conscientizar as pessoas de que nós precisamos da natureza e ela precisa de todas(os) para que tudo possa continuar em equilíbrio? Essa inquietação passou a movimentar o grupo, que delimitou o objetivo geral e os específicos de uma 
pesquisa qualitativa, bibliográfica, de campo e experimental. O objetivo geral foi assim redigido: Conhecer as diferentes formas de vida existentes, especialmente as borboletas, para respeitar os ecossistemas e encontrar maneiras de promover a sua preservação.

Já os específicos, foram os seguintes: organizar um caderno de campo para registrar as descobertas e como o projeto foi sendo construído; separar e destinar corretamente os resíduos produzidos em sala de aula e em casa; conhecer e explorar o Guia Ambiental do Cidadão Igrejinhense para estar a par das ações de cuidado e de conscientização em andamento na cidade; fazer parceria com o Centro de Educação Ambiental Augusto Kampff com o projeto: CEAAK \& Escola em Ação; fazer formação específica a ser ministrada pela Patrulha Ambiental (PATRAM) para ser um(a) Patrulheiro(a) Ambiental Mirim e, assim, disseminar a ideia de proteção ao meio ambiente e respeito à biodiversidade; convidar o Secretário de Planejamento e Meio Ambiente da cidade para fazer uma palestra após estarmos formados como patrulheiros ambientais e, então, podermos contribuir com os nossos conhecimentos; organizar um fórum de projetos investigativos em Ciências quando cada um(a) socializará na turma e na escola o que descobriu a partir do seu assunto individual dentro do tema biodiversidade e divulgar os resultados das nossas ações no painel: CEAAK \& Escola em Ação e no site da escola.

As buscas por respostas começaram e o ano letivo de dois mil e dezenove foi todo dedicado a essa investigação, pois a cada desafio vencido surgia outro que fazia com que a teia do conhecimento sempre estivesse em processo de ampliação. Momentos como a palestra com estudantes, da turma da professora Priscila, que vieram compartilhar suas descobertas sobre as mariposas, a palestra com um estudante de graduação sobre o destino correto dos resíduos, a palestra com a bióloga e professora da escola Letícia Passos que trouxe subsídios a partir de questionamentos que a turma havia feito previamente sobre a diferença entre borboletas, mariposas e libélulas, a observação do desenvolvimento das fases da metamorfose da borboleta e da libélula em um experimento em sala de aula e palestras com o professor, da nossa escola, Jair Rolim da área da Geografia, explicando sobre o universo e o sistema solar, foram estruturantes. A partir daí, outros links foram surgindo: Curso de formação de Patrulheiros Ambientais Mirins (PATRAM), visita guiada ao Gramado ZOO, Palestra do Secretário Municipal de Planejamento e Meio Ambiente, fórum de projetos 
investigativos da turma, registros no site da instituição, participação na primeira Mostra Científica da escola e participação no Painel do CEAAK, espaço para socializar projetos entre escolas.

A parceria com o CEAAK, espaço vinculado ao sistema municipal de ensino da cidade, aconteceu em encontros bimestrais pensados a partir do tema biodiversidade. $\mathrm{O}$ projeto CEAAK \& Escola em Ação objetiva promover a conscientização sobre os cuidados com o meio ambiente e oferece aos estudantes vivências nas quais possam fazer interferências na natureza que resultem em experiências positivas, de posicionamento crítico e de multiplicadores de novas possibilidades. Os encontros foram conduzidos pelo biólogo e professor Lúcio Barth e aconteceram na sede e no espaço ao ar livre da instituição que tem o privilégio de estar localizada em uma grande área verde próxima ao rio da cidade e de um de seus afluentes: o arroio Koetz, que, após percorrer vários quilômetros, passa próximo à escola Berthalina.

Paralelo a isso, o caderno de campo da turma foi se tornando fonte de registro e de reflexão, pois a cada dia, de fevereiro a dezembro, sempre houve algo a ser destacado, comentado, escrito e revisitado. Os momentos de discussão, de argumentação e de posicionamento a favor ou contra uma ou outra teoria acerca do surgimento do planeta, por exemplo, passaram a ser estruturantes quanto à alfabetização científica do grupo, pois somente um estudante havia participado anteriormente de um projeto científico, o que se caracterizou como um movimento novo para a turma.

Porém, “A grande mudança no papel do professor no ensino por investigação é ser o promotor de oportunidades para novas interações entre os alunos e o conhecimento" (SASSERON, 2012, p. 12). E um dos possíveis resultados seria o entendimento do papel do professor no ensino por investigação, especialmente em tempos em que os resultados das pesquisas, muitas vezes, são apresentados e entendidos como mais importantes do que o processo de construção dos conhecimentos que emergem de um projeto. Dentro desse movimento pedagógico, a colaboração é essencial para que haja construção de novos conhecimentos, pois cada um dos envolvidos na comunidade de indagação dialógica, por meio da pesquisa-ação, tem espaço e oportunidades para ir se constituindo e para ir mostrando possibilidades aos demais. 


\section{ANÁLISE E DISCUSSÃO DO RELATO}

A proposta de trabalho por projetos investigativos, interdisciplinares e colaborativos privilegia a construção de conhecimentos, a autonomia de pensamento e a tomada de consciência de que cada um(a) é autor(a) de ações que objetivam uma interferência positiva no meio em que vive. Sendo assim, todos os momentos, desde a estruturação da pesquisa, desenvolvimento, considerações finais e ações de relevância social e ambiental são coletivos e colaborativos, pois tanto a busca de informações ou construção de dados, quanto os resultados obtidos, são socializados em grande grupo para que possa ir sendo de apropriação comum a todas(os) os integrantes da turma. Portanto, trata-se de uma produção científica resultante das ações do grande grupo, o qual, ao final do processo, se identificará como autor de um novo conhecimento que, por sua vez, poderá ser o ponto de partida para novas pesquisas.

Desse modo, a proposta de trabalho por projetos investigativos é um processo em que a construção dos conhecimentos acontece a partir da estruturação ou da ancoragem desses na bagagem que cada estudante traz consigo sobre o assunto que está mobilizando o grupo, mas tem, como mola propulsora, a curiosidade em torno do que desejam saber. Esse desejo impulsiona o grupo a acessar diferentes fontes de pesquisa: bibliográficas, virtuais, interpessoais, profissionais de áreas específicas e instituições que possam amparar o estudo. Enfim, são parcerias que auxiliam a tecer uma rede de conhecimentos novos que, antes de serem tidos como absolutos e verdadeiros, se voltam para as hipóteses iniciais para que possam ser confrontados e aí serem validados como científicos, pois fizeram todo um mapeamento do que esteve ao alcance e, a partir disso, criaram um novo registro. Trata-se de um registro legítimo, genuíno e único, feito em caderno de campo da turma, pois, mesmo que outras pessoas já tenham pesquisado sobre o assunto, o que esse grupo construiu é inédito e valida a caminhada que foi feita, pois traz em si uma parte da história de vida pessoal e escolar de todos os envolvidos.

Nisso reside a beleza e o encantamento que a escola pode proporcionar aos estudantes, pois ela é um espaço de excelência na construção do saber e somente nela se reúnem profissionais de áreas pedagógicas e de áreas específicas que, juntos, podem dar asas ao interesse daqueles cujos olhos brilham quando tocados pela curiosidade e pelo desejo de saber. A escola então já não é mais uma gaiola, como cita Rubem Alves (2001), pois ela passa a ser asas e existe para encorajar o voo dos pássaros. 
Edição Especial: XVI Encontro sobre Investigação na Escola - EIE

O desenvolvimento deste projeto investigativo, interdisciplinar e colaborativo foi se constituindo em uma experiência envolvente, contagiante e significativa, em que os processos de alfabetização e de argumentação científica se tornaram visíveis. Essa visibilidade aconteceu especialmente durante o andamento do experimento que permitiu a observação das fases da borboleta e da libélula, durante a formação da PATRAM, durante o fórum (onde cada estudante socializou a sua pesquisa individual dentro do tema trabalhado) e durante o bate-papo que sucedeu a palestra do Secretário Municipal de Planejamento e Meio Ambiente da cidade.

Os estudantes se apropriaram dos conhecimentos construídos a partir das pesquisas e, ao colocarem suas contribuições ou questionamentos, trouxeram dados, nomes científicos e sugeriram propostas que mostraram seu comprometimento com a preservação da biodiversidade nos espaços, tanto pensando no presente quanto no futuro. "Eles realmente absorveram muito conhecimento" foi a fala do secretário, que os estimulou a continuarem pesquisando e se empoderando de conhecimentos, pois valorizou muito a escola como espaço de formação de pesquisadores, especialmente destacando a importância de um projeto interdisciplinar como o da turma, em que vários professores e colaboradores participaram e enriqueceram a experiência cujos resultados serão levados para a comunidade e farão a diferença na vida de muitas pessoas.

\section{CONSIDERAÇÕES FINAIS}

O protagonismo estudantil, a alfabetização e a argumentação científica, bem como a formação permanente de professores, descritos no projeto desenvolvido pelo quinto ano, traz um movimento importante para a escola: as parcerias pedagógicas interdisciplinares e colaborativas. A partir do momento em que o conhecimento ultrapassa a soleira da porta da sala de aula e oportuniza a todos os envolvidos um novo horizonte, não há mais um fazer pedagógico solitário por parte da titular unidocente da turma que, com seus pares de áreas especializadas, passa a promover um projeto interdisciplinar.

Sendo assim, por intermédio dos demais professores que se envolveram no itinerário, isso se espalha como sementes ao vento e irradia uma esperança no sentido de procurar compreender melhor a escola como espaço de formação permanente de professores em comunidade e aí surge o movimento de pensar o desenvolvimento de projetos investigativos enquanto oportunidade potente para que os professores 
Edição Especial: XVI Encontro sobre Investigação na Escola - EIE

transformem as suas práticas em objetos de investigação. E foi esse movimento que fez com que os professores envolvidos no projeto aqui descrito procurassem partilhar experiências, planejar colaborativamente e ressignificar suas práticas em um viés dialógico e interdisciplinar.

Dentro dessa perspectiva de compreensão da importância da investigação das próprias práticas, torna-se relevante aproximarmos a escola da Universidade. Sendo assim, enquanto mestranda da Universidade Federal do Rio Grande - FURG, pude participar e divulgar na Escola Berthalina uma possibilidade real e concreta de formação continuada por meio do I Curso Online de Formação de Professores sobre Feiras e Mostras Científicas. Esse curso de extensão, aberto no Ambiente Virtual de Aprendizagem do Moodle, no período de abril a maio do ano letivo de dois mil e vinte, oportunizou, para quatorze colegas docentes, o início de uma caminhada que, nos meses seguintes, seguiu ampliando horizontes, já que alguns deles, que também lecionam para turmas do Ensino Médio noturno, desenvolveram projetos interdisciplinares, dentro de um contexto dialógico e colaborativo com seus pares.

Acreditamos que, ao final da formação de $40 \mathrm{~h}$, os participantes avançaram na sua compreensão acerca da importância do trabalho colaborativo em relação aos projetos investigativos em Ciências. Além disso, encontraram subsídios teóricos consistentes para ir redefinindo rotas que contemplem a valorização do processo e não somente o resultado das pesquisas, teorizando sobre a continuidade da proposta de realização de Mostra Científica na escola.

Sempre que se pensa sobre um objeto aperfeiçoável, já se está para além do entendimento que tínhamos de início. Nesse caso, ao pensarmos sobre os projetos investigativos desde a sala de aula, em uma comunidade de indagação dialógica, estamos avançando individual e coletivamente em nossos entendimentos, e isso significa um salto qualitativo em nosso fazer pedagógico. O reflexo da ampliação de nossos horizontes pedagógicos nos permite conhecer processos de aprendizagem, ou seja, nos coloca em um outro espaço-tempo em que o estar inquieto nos impulsiona a buscar novos saberes-fazeres.

Dentro dessa perspectiva, posicionamo-nos a favor de uma metodologia ativa cuja gênese nos permite compreender como os sujeitos aprendem, como apreendem e como aprendem a aprender. Com esses entendimentos, já não seremos mais os mesmos e muito menos as nossas práticas, pois principalmente essas estarão permeadas de uma 
Edição Especial: XVI Encontro sobre Investigação na Escola - EIE

ISSN: 2595-4520 Vol. 4, n. 2. 2021

clareza pedagógica incontestável que já não concebe mais pensar somente no ensino. A comunidade de indagação dialógica nos possibilitou sair da nossa zona de conforto porque, na verdade, já não estávamos mais confortáveis lá e nos coloca na nossa zona de desenvolvimento potencial, para que, ao nos desafiarmos a compreender processos, possamos compreender que estamos constantemente em processo.

A partir daí, junto com nossos pares, colegas docentes inquietos e em formação continuada, bem como com as parcerias possíveis, estaremos em um tempo e em um espaço permanente de novas possibilidades teóricas e práticas, de renovação de nossos fazeres-saberes e de vivência de uma ação docente pautada no diálogo e na colaboração. O movimento formativo permanente representa o nosso desejo de, enquanto profissionais comprometidos, buscar compreender sempre mais sobre o que envolve a essência do trabalho relacionado aos projetos investigativos em Ciências.

\section{REFERÊNCIAS}

ALVES, Rubem. A escola que sempre sonhei sem imaginar que pudesse existir. São Paulo: Papirus, 2001.

CORÁ, Jeferson. A preocupação do poder público com a preservação da natureza em Igrejinha. Palestra ministrada no mês de dezembro de 2019.

FREIRE, Paulo. Pedagogia da autonomia: saberes necessários à prática educativa.

São Paulo: Paz e Terra, 1996.

GALIAZZI, Maria do Carmo. Indagações dialógicas com Gordon Wells. Rio Grande: Editora da Furg, 2016.

GARCIA, Priscila Debastiani. Voa, Voa Mariposa. Palestra ministrada pela turma do Segundo Ano de uma escola da rede particular da cidade em 21 de maio de 2019. GUIDOTTI, Charles dos Santos. A Investigação desde a sala de aula de Ciências: processo de autoformação com aperfeiçoamento teórico-prático de professores no

Cirandar. 241p. Tese de doutoramento em Educação em Ciências pela Universidade Federal do Rio Grande (FURG), Rio Grande, 2019.

GUIDOTTI, Charles dos Santos; ARAÚJO, Rafaele Rodrigues de. Mostras de ciências na escola: aspectos teórico-práticos da pesquisa em sala de aula. Revista Insignare Scientia - RIS, v.3, n.3. P. 46-63, 13 nov. 2020. 
Edição Especial: XVI Encontro sobre Investigação na Escola - EIE

INTEGRAL, Centro de referências em educação. Vídeo: A Escola Ideal. (2013).

9min50seg. Disponível em: https://educacaointegral.org.br/glossario/professormediador/. Acesso em: 06 jan. 2020.

KAMPFF, Centro de Educação Ambiental Augusto. Projeto CEAAK \& Escola em Ação: biodiversidade. Encontros nos meses de abril a novembro de 2019.

MOREIRA, Marco Antonio. A teoria de ensino de Bruner. São Paulo: Editora Pedagógica e Universitária, 1999.

MOREIRA, Marco Antonio. Teorias

de aprendizagem. São Paulo:

Editora Pedagógica e Universitária, 1999.

PASSOS, Letícia. Diferenças entre borboletas, mariposas e libélulas. Palestra ministrada em 28 de junho de 2019.

PIMENTA, Selma Garrido et al. Pesquisa colaborativa na escola como abordagem

facilitadora para o desenvolvimento profissional de professores. Faculdade de educação da Universidade de São Paulo: Relatório de pesquisa, 1999.

ROLIM, Jair Scheffer. Sistema solar. Palestras ministradas no mês de julho de 2019.

SASSERON, Lúcia Helena. O ensino por investigação: pressupostos e práticas. São Paulo: Licenciatura em Ciências - USP. Módulo 7, 2012.

VYGOTSKI, Lev Semionovich. A formação social da mente. São Paulo: Martins

Fontes, 1991. 